\title{
Humores e Temperamentos: CONSIDERAÇões SOBRE A TEORIA HIPOCRÁTICA
}

\author{
Cleiton Lopes Rodrigues*
}

\begin{abstract}
RESUMO
A teoria hipocrática dos quatro humores, presente na obra $D a$ Natureza do Homem, constitui o corpo humano a partir de quatro fluidos: sangue, fleuma, bile amarela e bile negra. De acordo com o tratado, a saúde seria mantida por um equilíbrio entre esses quatro humores. Alguns intérpretes afirmam que esses humores influenciam os temperamentos, concluindo assim, que determinadas representações mentais correspondem a elementos físicos. 0 presente artigo visa percorrer um trajeto histórico-filosófico das interpretações em torno da teoria humoral hipocrática, de modo a compreender como se deu o seu desenvolvimento para uma teoria temperamental.
\end{abstract}

Palavras-chave: humores; temperamentos; Hipócrates; Galeno.

\section{HUMORS AND TEMPERAMENTS: CONSIDERATIONS ON THE HIPPOCRATIC THEORY}

\begin{abstract}
The Hippocratic theory of the four humors, present in the work The Nature of Man, constitutes the human body from four fluids: blood, phlegm, yellow bile and black bile. According to the treatise, health is maintained by balancing these four humors. Some interpreters claim that these humors influence temperaments,
\end{abstract}

* FFLCH-USP. Estudante de graduação do curso de Filosofia da Faculdade de Filosofia, Letras e Ciências Humanas (FFLCH) da Universidade de São Paulo (USP). cleiton.lopes@usp.br

Revista Páginas de Filosofia, v. 9, n. 2, p. 109-120, jul.-dez. 2020 
thus concluding that certain mental representations correspond to physical elements. This article aims to cover a historical-philosophical path of interpretations around the hippocratic humoral theory, in order to understand how it developed into a temperamental theory.

Keywords: humors; temperaments; Hippocrates; Galen.

\section{INTRODUÇÃo}

Atualmente, o termo humor remete àquele estado de espírito no qual uma pessoa se afeta com algo ou alguém que se apresenta a ela. É comum, ainda, indicar ditos e gestos engraçados utilizados por profissionais da comédia a fim de despertar o riso em seus espectadores. Humor refere-se, portanto, a um temperamento no qual o indivíduo está inclinado a experimentar e se comportar conforme as representações do meio que o envolve. Nem sempre foi assim. Para o grego da era clássica, humor (hokótan) estava relacionado a substâncias fluidas corporais cujo equilíbrio resulta em sua saúde física. Assim, para o grego, dizer que alguém tem "bom humor" equivalia a dizer que seus fluidos estavam em pleno equilíbrio, e, portanto, estava saudável fisicamente; da mesma forma, dizer que alguém estava de "mal humor", era dizer que seu corpo sofria de alguma doença.

Hipócrates de Cós, famosíssimo médico do século V a.C., cuja influência de sua obra o levou a ser citado por filósofos como Platão ${ }^{1}$ e Aristóteles ${ }^{2}$, desenvolveu em seu tratado Da Natureza do Homem ${ }^{3}$ a tese que define o corpo humano como constituído por quatro humores: sangue, fleuma, bile amarela e bile negra. Para o médico de Cós, esses são os princípios elementares da physis do homem, e aquilo que determina a sua higidez ou a sua corrupção. Ele afirma, ainda, que cada um desses quatro humores corresponde a cada uma das estações do ano, e agem conforme tais climas. Assim, estes humores aumentam e diminuem com o ritmo das estações: fleuma, fria e úmida,

\footnotetext{
Cf. Protágoras 311b5-c2; Fedro 270c;

Cf. Política 1326a13-16

3 Há uma discussão em torno da autenticidade da obra que será brevemente exposta na seção seguinte.
}

Revista Páginas de Filosofia, v. 9, n. 2, p. 109-120, jul.-dez. 2020 
predomina no inverno; sangue, quente e úmido, na primavera; bile amarela, quente e seca, no verão; e bile negra, fria e seca, no outono.

Ocorre que Hipócrates, em sua obra, jamais relacionou a disposição física desses humores com os temperamentos que o indivíduo possa, eventualmente, sofrer. $\mathrm{O}$ seu tratado limita-se a expor tão somente a estrutura física e como ela se dá no que se refere à manutenção da saúde e cura de doenças do corpo. Diante disso, emerge a questão: Como se deu, na história do pensamento antigo, essa passagem de uma visão estritamente física para uma interpretação que relaciona o funcionamento do corpo com aspectos do caráter? 0 presente artigo visa expor brevemente uma leitura de alguns textos de autores do mundo antigo, de modo a preencher essa lacuna e compreender como se deu o desenvolvimento de uma teoria fluida para uma teoria temperamental.

Para isso, pretende-se partir de uma análise da concepção física hipocrática nos primeiros parágrafos do tratado Da Natureza do Homem, sua proposta peculiar de conceber a natureza humana, e as noções que envolvem a sua teoria humoral; e, após isso, apresentar trechos de textos de intérpretes da obra hipocrática, tais como Galeno e outros autores da antiguidade, pouco conhecidos, de um estudo minucioso elaborado pelo comentador e tradutor de Hipócrates, Jacques Jouanna. Por fim, espera-se confirmar a hipótese de que a teoria dos quatro temperamentos foi desenvolvida a partir de uma interpretação direta da própria teoria hipocrática.

Todavia, antes de adentrar no tema proposto, se faz necessário tecer algumas considerações acerca da autoria da obra na qual está inserida a teoria dos quatro humores, o tratado hipocrático intitulado Da Natureza do Homem.

\section{BREVES CONSIDERAÇões SOBRE A AUTENTICIDAdE DA OBRA}

Há uma larga discussão em torno da verdadeira autoria da obra $D a$ Natureza do Homem. 0 tratado é fortemente atribuído à Pólibo, discípulo e genro de Hipócrates. Isso se dá em razão do testemunho de Aristóteles, em História dos Animais (512b-513a), a qual o filósofo transcreve uma longa descrição dos vasos sanguíneos, retirado do parágrafo $11^{0}$ do texto de Da Natureza do Homem, incumbindo sua autoria a Pólibo. 
Todavia, o médico Galeno de Pérgamo, no século II a.C, contribuiu à difusão da obra e a atribui a Hipócrates. Ele escreveu comentários sobre vários tratados de Hipócrates, dentre eles, sobre Da Natureza do Homem. Para o médico de Pérgamo, o tratado é composto por três seções: a primeira corresponde aos parágrafos $1^{\circ}$ ao $8^{\circ}$, onde o médico de Cós anuncia sua concepção de natureza humana e afirma que o homem é formado por quatro humores. A segunda seção do comentário de Galeno corresponde aos parágrafos $9^{\circ}$ ao $15^{\circ}$, onde há uma longa discussão sobre os vasos sanguíneos. A terceira seção corresponde aos parágrafos $16^{\circ}$ ao $23^{\circ}$, que é dedicada à dieta de pessoas saudáveis de acordo com as estações ${ }^{4}$.

Apesar da citação de Aristóteles, Galeno está convencido da autenticidade da primeira parte da obra. Ele argumenta que o trabalho deve ser considerado legitimo, uma vez que tem como base todo o sistema de Hipócrates, acrescentando, ainda, que a primeira seção é referida por Platão na passagem 270 c do Fedro, sob a adução de que o método alugado por Platão é observado neste tratado. ${ }^{5}$

Littré (1839, p. 46) afirma que o argumento de Galeno é inconclusivo, demonstrando que método proposto por Platão no Fedro não se baseia em $D a$ Natureza do Homem, mas no tratado hipocrático $D a$ Medicina Antiga, onde Hipócrates expressa que não se pode conhecer a natureza do homem se não conhecermos a medicina. Nesse sentido, a citação de Platão não faz alusão a alguma obra intitulada Da Natureza do Homem, mas de um método que, ao considerar o corpo, observa as relações entre o homem e as demais coisas, declarando que obteremos sobre este objeto noções positivas apenas pelo método que ele indica. Em outras palavras, para Littré, a adução de Galeno não poderia ser verdadeira, uma vez que Platão não faz uma citação meramente textual, mas usa de um argumento que consiste em trazer de volta o estudo do corpo humano para compreender sua natureza.

Jouanna (1999, p.59), por sua vez, entende que o relato de Platão não traz nenhuma luz sobre a identificação de escritos autênticos,

GALEN. On Hippocrates' On the Nature of Man, §§ 9-11.

5 GALEN. On Hippocrates' On the Nature of Man, $\S \S 11-13$ e $\S \S 104-109$. Cf. CAIRUS, 2005, p. 39. 
podendo-se concluir, somente, que o método de Hipócrates era referenciado pelos seus contemporâneos:

A única conclusão que emerge disso com certeza é que o método de Hipócrates já era famoso o suficiente durante sua vida, e que um dos interlocutores de Sócrates poderia referir-se a ele como bem conhecido. ${ }^{6}$

De toda sorte, entre o que se conhece de Hipócrates e a obra atribuída a ele, resta uma lacuna que talvez jamais será preenchida, e, independentemente da autenticidade do escrito Da Natureza do Homem pertencer a Hipócrates ou a Pólibo, não há dúvida de que é possível referir-se a ele como um tratado hipocrático no sentido amplo do termo e, por esta razão, é referido como parte do corpus hippocraticum.

\section{DA NATUREZA DO HOMEM E A TEORIA DOS QUATRO HUMORES}

Não há que se falar em natureza e como ela age sem que antes seja apontado o conceito de physis para o grego daquele tempo. No contexto dos chamados filósofos pré-socráticos, natureza designa um princípio gerador das coisas em que se unifica a multiplicidade destas. Platão vai orientar nas Leis que esses autores "entendem por natureza a geração das primeiras coisas."7 Natureza pode significar, ainda, a totalidade daquilo que é, pertencendo também ao psíquico, dando a ela um princípio inteligente que é reconhecido através de suas manifestações. Nas palavras de Bornheim (1972, p. 14):

Pensando a physis, o filósofo pré-socrático pensa o ser, e a partir da physis pode então aceder a uma compreensão da totalidade do real: do cosmos, dos deuses, e das coisas particulares, do homem e da verdade, do movimento e da mudança, no animado e o do inanimado, do comportamento humano e da sabedoria, da política e da justiça.

No entanto, o autor hipocrático ${ }^{8}$ não trata de uma natureza universal como fizeram os pré-socráticos, tampouco busca um princípio

6 Todas as traduções de trechos da bibliografia em inglês são de minha autoria.

$7892 \mathrm{c}$

8 Devido à obscuridade que atravessa a autenticidade da obra, usarei, a partir deste momento, o termo "autor hipocrático" sempre que me referir ao escritor do tratado Da Natureza do Homem. 
gerador das coisas, mas examina uma natureza particular e específica, a natureza humana. Nesse sentido, inicia o tratado Da Natureza do Homem anunciando que:

Quem costuma ouvir aqueles que falam sobre a natureza humana, além do que concerne à medicina, para ele, este discurso não é interessante de ser ouvido. Digo, pois, não ser o homem, por completo, nem ar, nem fogo, nem água, nem terra, nem nenhum outro elemento que não é manifesto no interior do próprio homem. Mas deixo de lado aqueles que querem falar tais coisas. (HIPÓCRATES, 2005, p. 42) ${ }^{9}$

Pode-se verificar que a obra se opõe à opinião daqueles que entendem ser a natureza humana composta de substâncias que não se encontram no interior do próprio homem. Portanto, para o autor hipocrático, há uma diferença fundamental entre a physis universal e a physis particular do corpo. Para Rebollo (2006, p. 54):

A physis do corpo é uma realização particular da physis universal e, enquanto tal é compreendida como princípio originário e organizador do corpo, que é o que concerne a medicina. Ela fornece a forma do corpo, isto é, o seu aspecto próprio ou particular e o seu comportamento.

Em continuidade, no segundo parágrafo da obra, o escritor hipocrático se contrapõe ao pensamento de que a constituição da natureza humana deriva de um único elemento. Afirma que isso não é possível, uma vez que, se assim fosse, o homem não sofreria, e, caso sofresse, haveria apenas um remédio para curá-la.

Por conseguinte, apresenta a natureza humana como a composição de quatro humores, isto é, fluidos corporais presentes no corpo, cuja mistura é causa de sua saúde ou de sua doença: "O corpo do homem contém sangue, fleuma, bile amarela e negra; esta é a natureza do corpo, através da qual adoece e tem saúde." (HIPÓCRATES, 2005, p. 43) E complementa:

9 Da Natureza do Homem, $\S 1^{\circ}$. Todas as traduções do tratado hipocrático Da Natureza do Homem utilizadas nesse artigo são de Henrique F. Cairus.

Revista Páginas de Filosofia, v. 9, n. 2, p. 109-120, jul.-dez. 2020 
Tem saúde, precisamente, quando estes humores são harmônicos em proporção, em propriedade e em quantidade e, sobretudo, quando são misturados. 0 homem adoece quando há falta ou excesso de um desses humores, ou quando ele se separa no corpo e não se une aos demais. (ibid.) ${ }^{10}$

No parágrafo 7ํㅡ, o autor hipocrático expõe, ainda, que cada um dos humores corresponde a cada uma das quatro estações, cada humor predomina na estação que compartilha a mesma natureza. Desta forma: o sangue é quente e úmido, e predomina na primavera; a bile amarela é quente e seca, e predomina no verão; a bile negra, fria e seca, predominando no outono; e fleuma, frio e úmido, predominando no inverno. (HIPÓCRATES, 2005, p. 45) Portanto, boa saúde é definida como o equilíbrio e mistura dos humores, enquanto seu desequilíbrio e separação são as causa da doença, e para evitar esse desequilíbrio, o médico recomendaria modificar o regime do paciente de acordo com as estações do ano.

Galeno, ao comentar o tratado Da Natureza do Homem, explica que os corpos são afetados pela composição do ar que os rodeia, sendo secos em misturas secas de ar, molhados em misturas úmidas, e igualmente aquecidos em misturas quentes e resfriados em misturas frias. Assim, uma vez que o inverno é úmido e frio, a fleuma, sendo úmida e fria, aumenta, ocorrendo o mesmo com as outras estações e humores. ${ }^{11}$

Defende que cada um dos humores é dominado por cada um desses atributos, de modo que não são inatos a ele. Aduz que se um humor fosse apenas um frio extremo - ou o calor, ou a secura, ou a umidade - deixariam de ser fluidos e seriam corpos sólidos. Afirma, ainda, que esses atributos estão presentes, em alguma medida, em cada um dos quatro humores, razão pela qual é necessária a mistura e equilíbrio desses fluídos. ${ }^{12}$

No entanto, a partir da teoria hipocrática dos quatro humores, Galeno entende que há um sistema de correspondências entre os humores e os caráteres, dos quais não há vestígio no tratado hipocrático:

10 Da Natureza do Homem, §1ㅇ.

11 GALEN. On Hippocrates' On the Nature of Man, §§87-91.

12 GALEN. On Hippocrates' On the Nature of Man, §§95-97.

Revista Páginas de Filosofia, v. 9, n. 2, p. 109-120, jul.-dez. 2020 
É necessário que seja explicado novamente que neste relato os caracteres da alma seguem as misturas no corpo. [...] Sendo isso assumido, portanto, o caráter agudo e inteligente da alma será devido ao humor bile, o caráter firme e constante devido ao humor melancólico, e o caráter simples e estúpido devido ao sangue. A natureza da fleuma é extremamente inútil na formação do caráter. ${ }^{13}$

Seguindo esse raciocínio, é possível notar um primeiro esforço para unir a teoria humoral hipocrática a uma teoria do caráter. 0 estudo de Galeno do tratado Da Natureza do Homem permitiu relacionar o que, até então, estava somente para elementos físicos fluídicos do corpo humano com os temperamentos e disposições que interferem no modo como alguém interpreta o mundo. Contudo, embora Galeno se apoie na ideia de que as características da alma seguem as misturas do corpo, ele não aplica essa ideia a todos os humores hipocráticos, pois, para ele, a fleuma não influencia no caráter.

Ocorre que essa relação entre humor e temperamento ainda não está sistematicamente desenvolvida em Galeno. Com efeito, apenas na medicina grega da antiguidade tardia que a teoria dos quatro temperamentos (sanguínea, fleumática, biliosa e melancólica), com todas as suas características físicas e morais, encontraria plena expressão.

Jouanna (2012, pp. 341-359.) apresenta um estudo que reúne alguns textos gregos semelhantes em conteúdo e terminologia no que se refere à sistematização e desenvolvimento da teoria dos quatro humores com uma teoria dos temperamentos. São seis textos gregos que seguem o mesmo raciocínio: um tratado anônimo chamado Sobre a Constituição do Universo e do Homem (p. 342); uma carta fragmentária atribuída ao teólogo João Damasceno sobre o que é ser um ser humano (p. 343-4); uma carta pseudo-hipocrática a Ptolomeu chamada Sobre a Constituição do Homem (p. 345); uma passagem de um tratado chamado Natureza do Homem de Melécio, o monge (p. 346); outra passagem de um tratado pseudo-galênico chamado Sobre os Humores (p. 347), e; uma passagem sobre os quatro temperamentos extraída de um tratado atribuído a Hipócrates, intitulado Sobre a Formação do Homem, encon-

13 GALEN. On Hippocrates' On the Nature of Man, §§95-97

Revista Páginas de Filosofia, v. 9, n. 2, p. 109-120, jul.-dez. 2020 
trado num manuscrito do século XV e mantido na Biblioteca Nacional da França (p. 351).

Tais escritos estabelecem uma equivalência pós-galênica entre os elementos do universo e os elementos do homem, ou seja, para cada um dos quatro elementos do universo (ar, fogo, terra, água) corresponde no homem cada um dos quatro humores (sangue, fleuma, bile amarela e bile negra). Todavia, a maior inovação está no paralelo dos temperamentos em comparação com a teoria humoral hipocrática.

1. Aqueles que são compostos de sangue são sempre amigáveis, fazem piadas e dão risadas;

2. Aqueles que são compostos de bile amarela são de temperamento amargo e ousado;

3. Aqueles que são compostos de bile negra são indolentes, pusilânimes e doentes;

4. Aqueles que são compostos de fleuma são desanimados, esquecidos; (JOUANNA, 2012, p. 342)

Esses textos colocam a teoria dos quatro temperamentos dentro de um sistema da teoria dos quatro humores. A descrição apresenta as qualidades físicas ou morais de cada temperamento por uma série de adjetivos. Assim, a semelhança é evidente entre esses textos gregos e sua discussão dos quatro temperamentos, não apenas em seu conteúdo, mas também em seu vocabulário, apresentando a teoria dos quatro humores e incluindo uma teoria dos quatro temperamentos.

\section{CONSIDERAÇões FINAIS}

Em que pese o testemunho aristotélico que confere a autoria da obra Da Natureza do Homem à Pólibo - ou pelo menos parte dela -, parece impossível nos dias atuais atestá-la. Contudo, é inegável que concerne a uma obra hipocrática, e mais do que isso, é incontroverso que o verdadeiro autor do tratado - seja Hipócrates ou Pólibo - buscava expor conceitos cujo conteúdo remetia a uma tradição médica consagrada na pessoa de Hipócrates de Cós. Enquanto herdeiro dessa tradição na antiguidade tardia, o médico Galeno crê ser inquestionável a legitimidade da primeira parte do trabalho, sobretudo por ser construído numa base sistematicamente hipocrática. Diante disso, é possível 
seguir o entendimento majoritário e considerar a obra Da Natureza do Homem como parte do corpus hippocraticum em razão de seu conteúdo apontar para princípios hipocráticos.

Dado o conceito geral de physis para o grego antigo de um lado, e a noção de physis trabalhada na obra de outro, é possível considerar que o autor hipocrático não tinha em mente qualquer relação entre os humores, ou seja, os fluidos corporais e um sistema de temperamentos. Embora a ideia de natureza no contexto grego envolva também experiências emocionais, de onde se poderia deduzir carácteres morais e os próprios temperamentos, o texto hipocrático revela, logo em seu primeiro parágrafo, uma proposta que envolve tão somente a constituição e funcionamento do corpo humano enquanto tal.

Ademais, o autor hipocrático é enfático ao limitar a sua arkhé a quatro elementos inerentes ao corpo, correspondendo-os, quando muito, a influências presentes na natureza física das quais relacionam os quatro humores às estações do ano. Enquanto tratado médico num tempo em que a medicina estava em seu pleno desenvolvimento, a preocupação hipocrática se restringe a conhecer a constituição física do homem, de modo que isso possibilite o aprimoramento de técnicas que garantam a saúde física do indivíduo, e quais as precauções deveriam ser tomadas em meio ao universo físico que o envolve.

Ao receber esse legado numa época posterior, Galeno é capaz de fortalecer tal potencialidade teórica, mantendo o que nela há de substancial, e aprimorando o que nela carece de atualização. Muito embora em Galeno ainda não haja uma sistematização completa daquilo que seria uma interligação entre a teoria dos quatro humores e uma teoria dos temperamentos, é possível perceber um esforço para unir a teoria hipocrática dos fluidos a certos carácteres morais, incutindo, em alguma medida, influências físicas às representações mentais.

Será em tempos pós galênicos que os laços da teoria hipocrática dos quatro humores e de uma teoria dos temperamentos serão definitivamente atados. Os textos gregos antigos apresentados por Jouanna elucidam a questão, na medida em que apresentam de forma sistemática - e mais aproximada - a noção contemporânea de humor ao reunir os quatro fluidos do tratado Da Natureza do Homem e corresponde-los a 
diversas características temperamentais que coincidem em conteúdo e vocabulário.

Assim, diante do exposto, é possível crer que a tese hipocrática dos quatro humores presente na obra Da Natureza do Homem, é a substância teórica para a construção de uma teoria temperamental que une humor - enquanto fluido corporal - e temperamento - enquanto disposição emocional para sofrer ou agir de determinada maneira. Tal desenvolvimento ocorreu em razão da potencialidade que a teoria humoral hipocrática carrega em si, bem como da necessidade de incorporá-la às questões de tempos posteriores à que foi instituída.

\section{REFERENCIAS}

ARISTÓTELES. História dos Animais, Livros I-VI; Lisboa: Imprensa Nacional, 2006. ARISTÓTELES. Política; Tradução de Antônio Campelo Amaral e Carlos Gomes. Vega, 1998.

BORNHEIM, Gerd A. Os filósofos pré-socráticos; introdução, tradução e notas de Gerd A. Bornheim. 2a ed. São Paulo, Cultrix. 1972.

CAIRUS, Henrique F. Textos hipocráticos: o doente, o médico e a doença. / Henrique F. Cairus e Wilson A. Ribeiro Jr. Rio de Janeiro. Editora FIOCRUZ, 2005.

GALEN. On Hippocrates' On the Nature of Man. Translated by W. J. Lewis with the assistance of J. A. Beach. Disponível em: http://www.ucl.ac.uk/ ucgajpd/medicina\%20 antiqua/tr_GNatHom.html. Acesso em: 01 de maio de 2018.

HIPÓCRATES. Da Natureza do Homem; In: Textos hipocráticos: o doente, o médico e a doença. Tradução de Henrique F. Cairus. Rio de Janeiro: Editora FIOCRUZ, 2005. p. 39-59.

JOUANNA, Jacques. Hippocrates. Translated by M. B. DeBevoise. The Johns Hopkins University Press. 1999.

JOUANNA, Jacques. The legacy of the Hippocratic treatise The Nature of Man: The Theory of the four humors; In: Greek medicine from Hippocrates to Galen: selected papers. edited with apreface by Philip van der Eijk, translated by Neil Allies. Brill. Leiden-Boston. 2012. pp. 335-359.

KERÉNYI, K. Arquétipos da Religião Grega; Tradução de Milton Camargo Motta. Petrópolis, RJ: Vozes, 2015.

LITTRÉ, E. Oeuvres complètes d'Hippocrate I. Paris: Baillère, 1839. 
PLATÃo. Fedro; In: Diálogos V. Tradução de Carlos Alberto Nunes. Belém: UFPA, 1975. PLATÃO. Leis; In: Diálogos XII-XIII. Tradução de Carlos Alberto Nunes. Belém: UFPA, 1975.

PLATÃO. Protágoras; organização e tradução Daniel R. N. Lopes. - 1. Ed. - São Paulo: Perspectiva: Fapesp, 2017.

REBOLLO, Regina Andrés. 0 legado hipocrático e sua fortuna no período greco-romano: de Cós a Galeno. Scientlae Studia. São Paulo. 2006. 